\title{
O PIB do agronegócio no estado de Minas Gerais: uma análise insumo-produto
}

\author{
Aline Cristina da Cruz ${ }^{1}$ \\ Erly Cardoso Teixeira ${ }^{2}$ \\ Marília Fernandes Maciel Gomes ${ }^{3}$
}

\begin{abstract}
Resumo: Neste trabalho, foram avaliadas as transformações na estrutura produtiva do agronegócio de Minas Gerais, segundo as definições de agregado I (fornecedor de bens e insumos para a agropecuária), agregado II (agropecuária), agregado III (processamento e industrialização agrícolas) e agregado IV (distribuição agrícola). Para isso, foi utilizada a matriz de insumo-produto de Minas Gerais, de 1999. O agronegócio gerou rendas equivalentes a 29,76\% do PIB de Minas Gerais e 9,6\% do PIB do agronegócio nacional. Do PIB do agronegócio mineiro, os setores fornecedores de insumos para a agropecuária participaram com 20,73\%; a agropecuária, com 27,53; e as atividades de processamento, industrialização e distribuição, com 51,75\%. A economia mineira apresentou características de economia alimentar industrializada, considerando a participação da produção agropecuária próxima de um terço do valor total do agronegócio. Tais resultados são significativos e evidenciam o grau de importância do agronegócio ao desenvolvimento da economia mineira.
\end{abstract}

Palavras-chaves: agronegócio, Minas Gerais, insumo-produto.

Abstract: Agribusiness productive structures and its changes in Minas Gerais state were analyzed in this study, according to following aggregate definitions: aggregate one (suppliers of input and goods for agricultural sector); aggregate two (agricultural production); aggregate three (processing and industrialization agricultural); and aggregate four (agricultural distribution). For this purpose, the 1999's input-output table of Minas Gerais state was used.

\footnotetext{
${ }^{1}$ Professora Assistente, Departamento de Ciências Econômicas, Universidade Federal de São João Del Rei. E-mail: alinecruz@ufsj.edu.br

2 Ph.D. Economia Rural, Professor Titular da Universidade Federal de Viçosa, Departamento de Economia Rural. E-mail: teixeira@ufv.br

${ }^{3}$ Doutora em Economia Rural, Professora Adjunta da Universidade Federal de Viçosa, Departamento de Economia Rural.E-mail:mfmogomes@ufv.br
} 
Incomes generated by agribusiness represented 29.76 percent from the GDP (Gross Domestic Product) in Minas Gerais state and 9.6 percent from the GDP in the national agribusiness. As for GDP from Minhas Gerais state, agricultural input supplier sectors reached 20.73 percent; agricultutural sector (27.53 percent); processing, industrialization and distribution activities (51.75 percent). The Minas Gerais state economy was characterized as an industrial food economy due to its agricultural production near of one-third of the total agribusiness value. The results are relevant and emphasize how important is the agricultural sector for the development of the economy in Minas Gerais state.

Key-words: agribusiness, Minas Gerais, input-output.

Classificação JEL: R15, R11, R58.

\section{Introdução}

A globalização da produção e de capital, na década de 90 trouxe, como conseqüência, a intensificação da concorrência, o que provocou dissolução de segmentos do agronegócio com pouca vantagem competitiva e com menor capacidade de adaptação e acesso aos novos mecanismos de inserção no mercado. A abertura dos mercados exigiu do agronegócio e dos demais setores maior otimização de suas unidades produtivas, visando à elevação da competitividade. O Plano Real de Estabilização Econômica em meados dos anos 90 teve vários efeitos sobre o setor agropecuário e sobre as atividades ligadas a este. Foi observada elevação dos preços de insumos, de forma generalizada, o que favoreceu as atividades dos setores a montante do agronegócio, ou seja, dos setores que ofertam insumos e implementos à agropecuária. No entanto, os preços dos alimentos permaneceram relativamente estáveis no período, apesar do aumento da demanda interna, reduzindo a rentabilidade e a eficiência de atividades com baixa competitividade.

Fica evidente que o novo padrão de competição revela maior segmentação e especialização do mercado de commodities, com o objetivo de melhorar a qualidade e aperfeiçoar outras características dos produtos. Além disso, o padrão de consumo brasileiro vem revelando maiores exigências com a qualidade e procedência do produto, o que exige, portanto, avanços no processo de reestruturação produtiva do agronegócio. A tendência é de concentração das agroindústrias, maior verticalização da produção e formação de grandes conglomerados, nos quais se evidenciam novas formas de organização dos processos produtivos e do trabalho. Em suma, todas essas transformações tendem a promover impactos na estrutura e no desenvolvimento do agronegócio de Minas Gerais.

Outros questionamentos sobre o agronegócio de Minas Gerais são igualmente relevantes, tais como sua dimensão econômica e sua contribuição para a economia 
do estado, além da avaliação de sua participação na formação do agronegócio do País. É importante, ainda, determinar o agregado do agronegócio que concentra maior volume de produção e, portanto, detém maior representatividade. Para responder a essas questões, o cálculo do PIB (Produto Interno Bruto) do complexo agroindustrial é essencial, visto que trata-se de um agregado econômico de grande importância para a identificação das transformações da estrutura produtiva, já que oferece suporte à formulação e ao direcionamento de políticas. Seguindo essa linha de pesquisa, existem diversos estudos, com diferentes objetivos, que avaliam o agronegócio em níveis regional e nacional. As análises são feitas sob a ótica de quatro grandes setores interligados, que são: agregado I (indústrias fornecedoras de bens de capital e insumos para a agropecuária), agregado II (agropecuária), agregado III (processamento e industrialização de bens agrícolas) e agregado IV (distribuição de bens agrícolas). Entre os trabalhos que calcularam a participação e a evolução do agronegócio no Brasil, podem-se citar os de Santana (1994), Furtuoso et al. (1998), Guilhoto et al. (2000), Montoya e Guilhoto (2000) e Nunes e Contini (2001).

Em análise regional, Parré (2000) analisou a evolução do agronegócio das cinco macrorregiões do Brasil, de 1985 a 1995, e afirmou que houve redução na participação do PIB agronegócio no PIB nacional no período. Parré e Guilhoto (2001), em estudo sobre a importância do agronegócio para o Sul, revelaram que a região participou com parcela de 30\% do agribusiness brasileiro. Porsse (2003) realizou este estudo para o Rio Grande do Sul em 1998 e concluiu que o agronegócio representou $29,5 \%$ do PIB do estado.

Figueiredo et al. (2005) mostraram a importância dos setores ligados à atividade primária para a economia de Mato Grosso e definiram alguns setores agrícolas e outros diretamente relacionados com estes como setores-chave ou pólos de desenvolvimento econômico. O trabalho de Neto e Costa (2005) mostra o dimensionamento do PIB do complexo agroindustrial em Pernambuco e seus resultados ressaltam a importância do setor para esse estado. A participação do agronegócio pernambucano no PIB estadual é três vezes maior que a do PIB do setor agropecuário.

No caso de Minas Gerais, são escassos os levantamentos sobre o comportamento do agronegócio. As pesquisas disponíveis, geralmente, apresentam problemas de abrangência e periodicidade. Fernandes (1997) usou as visões sistêmicas presentes nas matrizes de insumo-produto de 1980 e 1996, disponibilizadas pelo Banco de Desenvolvimento de Minas Gerais (BDMG). O estudo ressalta a forte especialização mineira na produção de bens intermediários, além da maior dependência do mercado externo, os quais ocupam o segundolugar no ranking dos estados com maiores volumes de exportação.

Diawara (2002) analisou o agronegócio mineiro, no mesmo período de Fernandes (1997), isto é, nos anos de 1980 e 1996, e utilizou também as matrizes disponibilizadas pelo BDMG, com o intuito de analisar a evolução da composição do agronegócio. Os resultados mostram aumento na parcela dos setores que ofertam 
insumos agrícolas (agregado I) e redução na contribuição dos setores de processamento e industrialização (agregado III) e distribuição de bens agrícolas (agregado IV) quando comparado 1996 com 1980. O estudo mostrou, também, diminuição da contribuição do agronegócio no PIB estadual entre 1980 e 1996. No entanto, o autor identificou, como limitação de pesquisa, a impossibilidade de a análise ser feita com base nos preços a custo de fatores. O autor realizou o dimensionamento com base nos preços de mercado, ou seja, não foram excluídos os impostos indiretos líquidos que incorrem sobre a produção. Mais especificamente, esse estudo fez o cálculo do PIB a preços finais pagos pelo consumidor, que inclui os impostos indiretos que incidem sobre os produtores. Quando feita a exclusão do total correspondente aos impostos líquidos, encontra-se o PIB a custo de fatores. Ademais, a metodologia usada no trabalho apresenta alguns problemas de superestimativas, além da dificuldade de estimar a renda do agregado I com base no valor adicionado, o que será discutido na seção metodológica deste artigo.

O presente estudo visou à caracterização da estrutura produtiva do agronegócio mineiro no ano de 1999, a partir da definição de sua dimensão econômica e suas contribuições para a economia do estado e para o agronegócio nacional. Ademais, objetivaram-se sobrepor alguns obstáculos presentes no trabalho de Diawara (2002). Em primeiro lugar, usa-se uma metodologia que apresenta alguns avanços em relação aos métodos anteriores. Em segundo, o período de análise deste trabalho é o ano de 1999, visto que são as informaçóes disponíveis mais atualizadas. Em terceiro, a mensuração do PIB do agronegócio, feita neste trabalho, condiz com os preços a custo de fatores, o que é correto quando calculado o PIB sob a ótica da renda.

No que se refere à estrutura do trabalho constam, além desta introdução e das considerações finais, mais três seções. Na seção 2, discute-se o modelo teórico de insumo-produto e, na terceira, o método de dimensionamento do agronegócio em Minas Gerais. Na quarta seção são apresentados os resultados obtidos.

\section{Teorias da análise de insumo-produto}

O referencial teórico deste estudo está relacionado com as teorias de matriz insumo-produto, cujas origens estão nos estudos de Leontief, datados de 1930. Leontief (1983) aplicou a teoria econômica do equilíbrio geral (interdependência geral) em análise empírica das inter-relações das atividades econômicas de uma nação, concentrando-se na idéia de fluxo circular. A teoria de insumo-produto baseia-se em alguns pressupostos que correspondem à simplificação do modelo walrasiano, que são equilíbrio geral na economia em dado patamar de preços, ausência de ilusão monetária, retornos constantes à escala e preços constantes.

A matriz de insumo-produto (MIP) de Leontief foi criada para descrever os fluxos de bens e serviços entre os setores da economia do país, em valores 
monetários, durante certo período. Embora criada inicialmente para estudo das economias das nações, a matriz de insumo-produto vem sendo adaptada para identificar as relações intersetoriais presentes nas economias de regiões e, ou, de estados. O modelo básico empregado em ambas as dimensões é semelhante e ocorre no sistema articulado por grupo de setores. Se por um lado os setores ofertam bens e serviços aos demais setores, por outro, também demandam bens e serviços dos outros setores. Segundo Langoni (1983), de acordo com Leontief, as vendas igualam-se às compras, as saídas são também entradas, ou os outputs são genuinamente inputs. A comercialização entre os setores econômicos de mercadorias e serviços é definida, conforme a teoria, em unidades físicas. No entanto, considerando os obstáculos de mensuração dos fluxos de compra e venda, como nos casos em que mais de um produto é vendido, a MIP é apresentada em termos monetários.

A análise da MIP permite construir o fluxo para processamento da produção e considera a desagregação dos seguintes elementos:

a) Demanda final: de acordo com as categorias de transações em cada um dos setores de atividade econômicas;

b) Valor agregado: obtido pelos setores nos seus respectivos processos produtivos; e

c) Demanda intermediária: definida pelos fornecimentos e aquisições de cada setor em relação a si próprio e aos demais.

As estimativas da demanda intermediária permitem a construção da matriz de coeficientes técnicos que informa, em termos relativos, a requisição de insumos necessários a cada setor para realizar a produção. A partir da matriz de insumo-produto é possível definir a matriz de requisitos diretos e indiretos, cujos elementos indicam os efeitos totais sobre a produção do setor, advindos de variação em qualquer componente da demanda final. Assim, um choque na demanda final do setor exigirá que este altere seu volume de insumos nas proporções indicadas na matriz de coeficientes técnicos para responder à demanda. Dado que os insumos são fornecidos por outros setores, estes também sofrerão alterações em suas vendas, e os efeitos da variação inicial na demanda final se propagarão por todo o aparelho produtivo. A Figura 1 permite visualizar as relações intersetoriais apresentadas na matriz de insumo-produto. Para simplificação consideram-se três setores econômicos. Os vetores-linha indicam os fluxos de vendas da produção do setor, nos quais se observam a distribuição do setor e suas relações com os demais, ou seja, as linhas apresentam as demandas intermediária e final pela produção do setor. Os vetores-coluna apontam as compras do setor necessárias para produção, considerando que a produção do setor requer insumos (nacionais e importados) provindos de outros setores, além do pagamento de impostos e remuneração dos insumos primários (valor adicionado). 

- O PIB do agronegócio no estado de Minas Gerais: uma análise insumo-produto

\begin{tabular}{|c|c|c|c|c|c|c|c|c|c|c|}
\hline \multirow{3}{*}{ Setores } & \multicolumn{9}{|c|}{ Compras (j) } & \multirow{3}{*}{\begin{tabular}{|c|} 
Valor \\
Bruto \\
Produção \\
$X_{i}$ \\
\end{tabular}} \\
\hline & \multicolumn{4}{|c|}{ Demanda intermediária } & \multicolumn{5}{|c|}{ Demanda final } & \\
\hline & Setor 1 & Setor 2 & Setor 3 & Subtotal & $\mathrm{C}$ & G & $\mathbf{I}$ & E & $\Sigma$ & \\
\hline Setor 1 & $\mathrm{x}_{11}$ & $\mathrm{x}_{12}$ & $\mathrm{x}_{13}$ & $\sum_{i, j=1}^{3} X_{1 j}$ & $\mathrm{C}_{1}$ & $\mathrm{G}_{1}$ & $\mathrm{I}_{1}$ & $\mathrm{E}_{1}$ & $\mathrm{Y}_{1}$ & $X_{1}$ \\
\hline 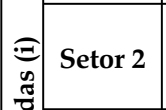 & $\mathrm{x}_{21}$ & $\mathrm{x}_{22}$ & $x_{23}$ & $\sum_{i, j=1}^{3} X_{2 j}$ & $\mathrm{C}_{2}$ & $\mathrm{G}_{2}$ & $\mathrm{I}_{2}$ & $E_{2}$ & $\mathrm{Y}_{2}$ & $X_{2}$ \\
\hline \begin{tabular}{|l|l|} 
& \\
& Setor 3
\end{tabular} & $\mathrm{x}_{31}$ & $\mathrm{x}_{32}$ & $x_{33}$ & $\sum_{i, j=1}^{3} X_{3 j}$ & $\mathrm{C}_{3}$ & $\mathrm{G}_{3}$ & $\mathrm{I}_{3}$ & $E_{3}$ & $\mathrm{Y}_{3}$ & $X_{3}$ \\
\hline Subtotal & $\sum_{i=1}^{3} X_{i j}$ & $\sum_{i=1}^{3} X_{i 2}$ & $\sum_{i=1}^{3} X_{13}$ & $\sum_{i, j=1}^{3} X_{i j}$ & $\sum_{i=1}^{3} C_{i}$ & $\sum_{i=1}^{3} G_{i}$ & $\sum_{i=1}^{3} I_{i}$ & $\sum_{i=1}^{3} E_{i}$ & $\sum_{i=1}^{3} Y_{i}$ & $\sum_{i=1}^{3} X_{i}$ \\
\hline Importação & $\mathrm{M}_{1}$ & $\mathrm{M}_{2}$ & $\mathrm{M}_{3}$ & $\sum_{j=1}^{3} M_{i}$ & & & & & & \\
\hline $\begin{array}{l}\text { Tributos } \\
\text { indiretos } \\
\text { líquidos }\end{array}$ & $\mathrm{T}_{1}$ & $\mathrm{~T}_{2}$ & $\mathrm{~T}_{3}$ & $\sum_{j=1}^{3} T_{i}$ & & & & & & \\
\hline $\begin{array}{c}\text { Valor } \\
\text { Adicionado }\end{array}$ & $\mathrm{VA}_{1}$ & $\mathrm{VA}_{2}$ & $\mathrm{VA}_{3}$ & $\sum_{j=1}^{3} V A_{i}$ & & & & & & \\
\hline \begin{tabular}{|c|} 
Valor bruto \\
da produção \\
$\mathrm{X}_{i}$ \\
\end{tabular} & $\mathrm{X}_{1}$ & $\mathrm{X}_{2}$ & $X_{3}$ & $\sum_{i=1}^{3} X_{j}$ & & & & & & \\
\hline
\end{tabular}

Fonte: PARRÉ (2000). Adaptação de Miller \& Blair (1985).

Figura 1. Matriz de insumo produto, do tipo Leontief, para três setores

Sob o conceito de vendas do setor (linhas), define-se a produção total do setor $\left(X_{i}\right)$ como a soma das demandas final e intermediária. Assim, considerando uma economia dividida em $n$ setores, definem-se as seguintes expressões:

$$
\begin{aligned}
& X_{i}=\sum_{j=1}^{n} X_{i j}+\left(C_{i}+I_{i}+G_{i}+E_{i}\right), j=1,2, \ldots, n . \\
& X_{i}=\sum_{j=1}^{n} X_{i j}+Y_{i}
\end{aligned}
$$

em que $X_{i}$ é a produção doméstica total do setor $i ; X_{i j}$, produção do setor $i$ usada como insumo intermediário pelo setor $j ; C_{i}$, produção do setor $i$ consumida pelas famílias; $G_{i}$, produção do setor $i$ consumida pelo governo; $I_{i}$, produção do setor $i$ destinada ao investimento; $E_{i}$, produção do setor $i$ que é exportada ;e $Y_{i}$, demanda final do produto $i$. 
As colunas, por sua vez, definem as compras de insumos intermediários do setor j e de todas as outras indústrias e correspondem a:

$$
X_{j}=\sum_{i=1}^{n} X_{i j}+M_{j}+T_{j}+V A_{j}, j=1,2, \ldots, n,
$$

no qual $X_{j}$ é a produção doméstica total do setor $j ; M_{j}$, total de importação realizado pelo setor $j$; $T_{j}$, total de impostos indiretos ${ }^{4}$ líquidos pagos pelo setor $j$; e $V A_{j}$, valor adicionado bruto gerado pelo setor $j$ (a preços de mercado).

Pode-se, assim, definir a seguinte igualdade básica:

$$
\begin{aligned}
& X_{1}+X_{2}+C+G+I+E=X_{1}+X_{2}+M+T+V A \\
& C+G+I+E=M+T+V A
\end{aligned}
$$

Rearranjando 3.1, tem-se:

$$
C+I+G+(E-V)=T+V A,
$$
bruto.

em que $(T+V A)$ é a renda nacional e $[C+I+G+(E-T)]]$, produto nacional

Definindo a parcela de insumo-produto do setor $i$ como diretamente proporcional à produção do setor $j$, tem-se que:

$$
X_{i j}=a_{i j} X_{j}
$$

em que $a_{i j}$ é o coeficiente técnico direto de produção ou de insumo-produto. Esse coeficiente indica a quantidade necessária de insumo do setor $i$ para a produção de uma unidade de produto final do setor $j$.

Com base na equação 4, pode-se definir o sistema aberto, de Leontief, como segue:

$$
\sum_{j=1}^{n} a_{i j} X_{j}+Y_{i}=X_{i}, i=1,2, \ldots, n .
$$

Em termos matriciais, a equação 5 consiste em:

$$
A X+Y=X,
$$

em que $A$ é a matriz de coeficientes diretos de insumo de ordem $(n \times n) ; X$, vetor coluna de ordem $(n \times 1)$ de valor bruto da produção; e, $Y$, vetor coluna de ordem $(n \times 1)$ de demanda final total.

\footnotetext{
${ }^{4}$ Constituem a parcela que diferencia os preços dos bens e serviços pagos pelas empresas dos preços recebidos pelos produtores. O ônus desses impostos transfere-se ao consumidor final, embora sua arrecadação seja feita por meio das empresas.
} 
Os coeficientes que compõem a matriz de coeficientes técnicos de produção encontrados na matriz A são definidos por:

$$
a_{i j}=\frac{x_{i j}}{X_{j}},
$$

em que $a_{i j}$ define o quanto de cada unidade de produção total do setor $j$ este demanda do setor $i$. Os coeficientes técnicos seguem a condição de $a_{i j}<1$ e $\left(1-a_{i j}\right)>0$. Cada coluna da matriz A representa a estrutura tecnológica do setor correspondente, de acordo com os pressupostos de retornos constantes de escala e utilização dos insumos em proporções fixas.

Partindo do pressuposto de que a demanda final ( $Y$ ) é exógena, para obter a produção total $(X)$, resolve-se a equação (5.1):

$$
X=(I-A)^{-1} Y,
$$

em que $(I-A)^{-1}$ é a matriz de coeficientes técnicos diretos e indiretos, ou a matriz de efeitos globais, conhecida também como matriz inversa de Leontief.

A matriz $(I-A)^{-1}$, definida como matriz $\mathrm{B}$, mostra todos os efeitos sobre todo o aparelho produtivo da economia, decorrentes de alteração quantitativa em qualquer um dos componentes da demanda final.

Segundo Haddad (1989), os elementos que compóem a matriz inversa de Leontief possuem certas característica, a saber:

a) $b_{i j} \geq a_{i j}$, isto é, cada elemento da matriz inversa é superior ou equivalente ao correspondente na matriz tecnológica, pois $b_{i j}$ define efeitos diretos e indiretos sobre a produção do setor $i$, para responder à demanda final de uma unidade monetária do setor $j$, enquanto o elemento $a_{i j}$ representa apenas os efeitos diretos;

b) $b_{i j}>0$, ou seja, os coeficientes da matriz inversa de Leontief são positivos, o que implica que os insumos são substitutos entre si, visto que os coeficientes técnicos de produção são fixos;

c) $b_{i j} \geq 1$ se $i=j$, isto é, os elementos da diagonal principal da matriz inversa têm valores superiores ou iguais à unidade. Desse modo, a variação de uma unidade monetária na demanda final de dado setor promoverá o acréscimo na produção de ao menos uma unidade monetária deste setor.

\section{Metodologia de dimensionamento do PIB do agronegócio}

O primeiro trabalho que aborda a expressão agribusiness data de 1957, segundo Araújo et al. (1990), e foi desenvolvido na Universidade de Harvard, tendo como resultado o livro Concept of Agribusiness, escrito por John Davis e 
Goldberg. A definição de agribusiness, feita por esses autores, era a de um complexo formado por todas as operações ligadas à produção e à distribuição de insumos agrícolas, bem como às operações de produção nas unidades agrícolas e às atividades relacionadas com armazenamento, processamento e distribuição dos produtos agrícolas e seus derivados. Essa definição confere ao setor da agropecuária a posição de núcleo do complexo agroindustrial. Os setores que fornecem insumos, implementos e máquinas para a agropecuária são chamados de setores a montante, enquanto os que processam, transformam e distribuem os produtos agropecuários constituem os setores a jusante. A utilização do conceito de agronegócio deve-se ao processo de evolução natural da agropecuária e de suas relações com as demais atividades, como as agroindústrias, os serviços financeiros, as atividades de pesquisa e desenvolvimento, além dos setores ligados à comercialização, à armazenagem e ao transporte de produtos rurais e agroindustriais.

A literatura aponta diversos estudos destinados à mensuração da importância do complexo agroindustrial ou agronegócio na economia brasileira. Dentre estes, constam Araújo et al. (1990), Santana (1994), Montoya e Guilhoto (2000), além de Parré e Guilhoto (2001), Montoya e Finamore (2001) e Neto e Costa (2005), que focaram a relevância do setor em níveis regionais. Esses estudos consideram a base teórica presente em Davis e Goldberg (1957), que se fundamentam em conceitos de relação insumo-produto, criados por Leontief, mas possuem algumas singularidades no que se refere à definição das atividades que compõem os setores a jusante e a montante no agronegócio.

Araújo et al. (1990), ao avaliarem o agronegócio brasileiro em 1980, concluíram que esse setor representava $46 \%$ dos gastos com consumo das famílias e era equivalente a 32\% do PIB brasileiro. Furtuoso (1998) e Parré (2000), que não dispunham de estatísticas que permitissem identificar a parcela do valor adicionado (VA) das indústrias ofertantes de insumos que é absorvida pelo setor rural, estimaram indiretamente o PIB do setor a montante do agronegócio brasileiro com base na composição do consumo intermediário da agropecuária. Essa sistemática considera, implicitamente, que os setores industriais fornecedores de insumos para a agropecuária apresentam um consumo nulo de produtos agrícolas. Nos modelos analíticos desses trabalhos são contabilizadas as importações da agropecuária de origem em outras regiões do País, além das importações do exterior. A justificativa é que tais compras de produtos importados são importantes devido ao fato de elas indicarem possíveis dependências da região com relação aos insumos necessários para o setor de produção rural. No cálculo do agregado II (produção agropecuária) considera-se o valor adicionado gerado pelos setores agropecuário e extrativo vegetal.

No estudo de Furtuoso (1998) é realizado o cálculo, separadamente, da indústria de base agrícola (agroindústria), então considerado como agregado III, e da distribuição final (agregado IV). No entanto, essa autora considera que os 
agregados III e IV compõem o setor a jusante do agronegócio. Na mensuração do agregado III, adota-se o valor adicionado do setor agroindustrial, que inclui os seguintes setores: fabricação de elementos químicos; indústria do café; beneficiamento de produtos vegetais; abate de animais; laticínios; indústria do açúcar; fabricação de óleos vegetais; madeira e mobiliário; e indústria têxtil. No caso do agregado IV, o dimensionamento é feito com base no valor adicionado dos setores de transporte; comércio e serviços. Considerando que o valor adicionado desses setores engloba todos os produtos do sistema econômico do País, ou da região, há necessidade de fazer uma ponderação (rateio), visando canalizar para o agronegócio somente o total referente à participação dos produtos agropecuários e produtos agroindustriais na demanda final de produtos do país (região).

Parré (2000) seguiu o modelo analítico de Furtuoso (1998), com algumas particularidades. A primeira refere-se aos setores que compõem a agroindústria. $\mathrm{O}$ autor adotou os critérios da Classificação Internacional Uniforme (CIIU versão 2). Neste caso, setor agroindustrial é formado pelos setores definidos no trabalho de Furtuoso (1998), com exceção do setor fabricação de elementos químicos, e inclui, também, os setores de artigos de vestuário e de produtos de couro e de calçados. A segunda particularidade que distingue tais pesquisas é o fato de Parré (2000) ter considerado como agregado III o setor a jusante do agronegócio, fazendo, assim, a junção dos agregados III e IV, definidos no trabalho de Furtuoso (1998).

Como instrumental analítico desta pesquisa, fez-se uso da metodologia de mensuração do agronegócio, proposta por Montoya e Finamore (2001), acrescida de algumas considerações próprias, com o objetivo de maior precisão e representatividade nas estimativas.

No que se refere à estimativa do Produto Interno Bruto (PIB) de Minas Gerais, foram seguidos os conceitos e procedimentos usuais de contabilidade nacional praticados pelo Instituto Brasileiro de Geografia e Estatística (IBGE). O PIB é um agregado macroeconômico que serve como medida síntese do resultado da atividade do conjunto da economia. É o agregado mais importante e corresponde à produção de todos os serviços e mercadorias finais dentro das fronteiras do País, em determinado período. O PIB do agronegócio equivale, portanto, à produção de todas as unidades produtivas de mercadorias e serviços ligadas ao setor da agropecuária, ou seja, as unidades a montante e a jusante.

O cálculo do produto interno segue a sistemática praticada pelo IBGE e pode ser quantificado a preços de mercado ou a custos de fatores de produção. A diferença entre esses conceitos é que o PIB a custo de fatores elimina o total referente aos impostos indiretos líquidos que incorrem sobre a produção. Nesta pesquisa, a mensuração do PIB do agronegócio é feita a custo de fatores. Considera-se o fato de que a geração da renda ocorre paralelamente ao processo de produção e exige, portanto, emprego de recursos de produção, como trabalho, 
capital, tecnologia e capacidade empresarial. Logo, as empresas mobilizam fatores e os remuneram sob forma de salários, juros, aluguéis e lucros, que representam os custos dos fatores.

Outra justificativa da estimativa do PIB a custo de fatores em vez do PIB a preços de mercado está ligada, segundo Rosseti (1980), ao papel do governo, que é considerado entidade que utiliza fatores de produção, e não propriamente fator de produção. No PIB a preços de mercado são incluídos os impostos indiretos pagos por produtores, que são transferidos aos compradores (inclusive governo) no ato da venda. Desse modo, o governo distorce os preços, visto que parte do poder de compra gerado na atividade produtiva é transferida ao agente público, sob forma de impostos indiretos (líquidos de subsídios). Sendo assim, o objetivo primordial é quantificar o PIB, evitando a situação em que nem todos os pagamentos feitos ao longo do processo de produção se destinem aos fatores produtivos. Logo, considerando o intuito de mensurar a remuneração dos fatores produtivos gerada em 1999 no agronegócio, a estimativa da renda ou da produção deve ser feita conforme a ótica dos custos de fatores. Especificamente, $\mathrm{o}$ Produto Interno Bruto a custos de fatores $\left(\mathrm{PIB}_{\mathrm{cf}}\right)$ é o valor adicionado a preços de mercado, subtraído dos impostos indiretos líquidos sobre produtos.

O cálculo do PIB pode ser efetuado segundo três diferentes óticas:

- Ótica da produção: PIB = valor da produção - consumo intermediário impostos indiretos líquidos = valor adicionado-impostos indiretos líquidos;

- Ótica da despesa: PIB = consumo das famílias + gastos do governo + formação bruta de capital fixo + variação de estoques + (exportações importações) - impostos indiretos líquidos; e

- Ótica da renda: $\mathrm{PIB}=$ remuneração dos assalariados + excedente operacional bruto - impostos indiretos líquidos.

Neste estudo, optou-se pela estimativa do PIB de Minas Gerais, segundo a ótica da produção. A justificativa é a necessidade de menor volume de informações estatísticas, além de esta ótica ser frequentemente usada na maioria dos trabalhos. É importante ressaltar ainda que, nesta pesquisa, considera-se o setor a jusante do agronegócio de Minas Gerais, conforme feito por Furtuoso (1998). Assim, a caracterização da estrutura de produção do agronegócio é a seguinte:

- Agregado I: indústria para a agricultura - engloba os fornecedores de insumos e fatores de produção para as propriedades rurais.

- Agregado II: representa a produção agropecuária.

- Agregado III: setores que recebem a produção agropecuária e agregam valor por meio do armazenamento e processamento aos bens agrícolas.

- Agregado IV: setores ligados à distribuição para o consumidor final dos produtos agroindustriais. 
Uma análise complementar é a possibilidade de comparar o grau de desenvolvimento das economias mediante avaliação da estrutura do agronegócio, tal como apontada em Malassis (1969), que sugeriu que fosse feita a caracterização de acordo com as participações de cada componente (agregado) na renda total do agronegócio. Segundo a pesquisa, o perfil de economia alimentar pré-industrial ou agrícola seria o caso em que o setor a montante (agregado I) concentraria, no máximo, 5\% do valor da renda total do agronegócio. Quanto ao agregado II, este atingiria 75\% da renda do agronegócio, seguido da importância relativa de $20 \%$ para os setores a jusante (agregados III e IV). No caso de economia alimentar industrializada, segundo o autor, os agregados I e II concentrariam em torno de $17 \%$ e $32 \%$, respectivamente, enquanto os agregados III e IV, ou setor a jusante, conjuntamente, participariam com $51 \%$ do valor total do agronegócio. À medida que o agregado II ou a produção rural iniciasse um processo de redução na concentração do valor total do agronegócio para renda de até um terço do valor total do agronegócio, a região estaria evoluindo do nível de economia pré-industrial para economia industrializada. No caso do agronegócio do Brasil em 2005, os setores que forneciam bens e serviços para a agropecuária (agregado I) concentraram $10 \%$ do produto do agronegócio, enquanto a agropecuária e os setores a jusante, contribuem com 30 e 60\%, respectivamente (Informativo Indicadores Rurais, 2006). Essas são características que definem o País como economia industrializada.

\subsection{Dimensionamento do Agregado I}

Nesta seção, é importante mencionar as diferenças entre as metodologias propostas em estudos anteriores, com vistas a justificar a escolha pelo método usado nesta pesquisa. Uma possibilidade para a quantificação do PIB do agregado I foi feita por Parré (2000) e Furtuoso (1998). Como não havia disponibilidade de estatísticas sobre a parcela do valor adicionado das indústrias fornecedoras de insumos para a agropecuária, o PIB do agregado I foi estimado com base na estrutura do consumo intermediário da agropecuária. As importações de insumos vindos do exterior e do resto do País, feitas pela produção rural do estado, são contabilizadas também, de modo que o PIB do agregado I é:

$$
\text { PIB do agregado } \mathrm{I}=\sum_{i=1} C_{i}+m_{1}^{P}+m_{1}^{R},
$$

na qual $C_{i}$ é o consumo intermediário da agropecuária; $m_{1}^{P}$, importações de outros estados; e $m_{1}^{R}$, importações do resto do mundo.

Vale ressaltar que a estimativa de PIB, sob a ótica da renda, deve ser feita pelo valor adicionado, e não com base no consumo intermediário, tal como foi feito no estudo de Parré (2000). Desse modo, neste estudo, optou-se pelo método 
proposto por Montoya e Finamore (2001), que estimaram a parcela do valor adicionado associada aos setores que fornecem insumos para a agropecuária (agregado I). Para superar a impossibilidade de se obterem, diretamente, estatísticas acerca da contribuição sobre o valor adicionado do setor agropecuário, dado pelo setor a montante do estudo de Parré, o método de Montoya e Finamore (2001) segue a hipótese de relação insumo-produto constante, a qual é definida pela relação entre consumo intermediário $(C I)$ e valor da produção $(V P)$, ou seja, $(C I / V P)$. De posse dos coeficientes, doravante denominados de coeficientes de valor adicionado, pode-se estimar a parcela do valor adicionado $(V A)$ de cada setor, a qual deve ser quantificada no agregado I. Mais claramente, mensura-se a parcela do valor de produção e da demanda intermediária de cada atividade do setor a montante do agronegócio mineiro, que equivale a

$$
\text { PIB do agregado } \mathrm{I}=\sum_{i=1}^{n}\left(\frac{x_{i 1}}{X_{i}}\right) V A_{i},
$$

em que $n$ é o número de setores fornecedores de insumos e bens de capital para a agropecuária; $x_{i 1}$, parcela do valor da produção do setor $i$, usada como consumo intermediário pela agropecuária; $X_{i}$, total do valor da produção do setor $i$; e $V A_{i}$, total do valor adicionado a custo de fatores do setor $i$, ou seja, está excluído o valor dos outros impostos líquidos sobre a produção, isto é, os outros impostos sobre a produção menos os outros subsídios à produção que recaem sobre o setor $i$.

Dado que o valor adicionado $(V A)$ resulta da diferença entre o total do valor de produção e o total do consumo intermediário $(C)$, pode-se reescrever a equação 7 da seguinte forma:

$$
\text { PIB do Agregado I }=\sum_{i=1}^{n}\left[\left(\frac{x_{i 1}}{X_{i}}\right) X_{i}-\left(\frac{x_{i 1}}{X_{i}}\right) C_{i}\right]
$$

em que $C_{i}$ é o total do consumo intermediário do setor $i ; \frac{x_{i 1}}{X_{i}}$, parcelas do valor de produção e de consumo intermediário de cada setor que fornece insumos para a agropecuária, o qual deve ser incluso no PIB do agregado I.

Outra questão relevante é a importância das compras feitas por Minas Gerais de insumos agropecuários de origem nos demais estados brasileiros, além das provindas do resto do mundo. A inclusão das importações inter-regionais e estrangeiras no PIB do agregado I é discutível devido ao conceito de produto interno. Vale lembrar que o PIB equivale à produção de todos os serviços e mercadorias finais dentro das fronteiras do país ou da região. Entretanto, ao 
desconsiderar essas trocas interestaduais e as relações externas do estado, pode-se incorrer em subestimativa de um setor importante do agronegócio, tal como é o setor a montante. Com base na relevância dos insumos de origem fora das fronteiras de Minas Gerais, neste trabalho, optou-se por incluir as importações do resto do Brasil e também as do exterior, tal como feito no estudo de Furtuoso (1998) e Parré (2000). Desse modo, a equação 8 é alterada para:

$$
\text { PIB do agregado } \mathrm{I}=\sum_{i=1}^{n}\left[\left(\frac{x_{i 1}}{X_{i}}\right) X_{i}-\left(\frac{x_{i 1}}{X_{i}}\right) C_{i}\right]+m_{1}^{R}+m_{1}^{P} .
$$

A opção de quantificação do agregado I, usada nessa pesquisa, segue a versão modificada do método de Montoya e Finamore (2001), conforme equação 9. Todavia, é mostrada, em seção posterior, a análise comparativa dos resultados segundo metodologia de Montoya e Finamore (2001), incluindo e excluindo as compras inter-regionais e as importações do exterior.

\subsection{Dimensionamento do Agregado II}

Para dimensionamento do agregado II (agropecuária), Montoya e Finamore (2001) utilizaram o valor adicionado a custo de fatores gerado pelo setor da agropecuária e extraíram desse o valor adicionado a custo de fatores gerado sobre os insumos adquiridos no próprio setor agropecuário, pois este já está incluso na mensuração do agregado I, conforme equação 9. Assim, o método evita dupla contagem. Mais explicitamente, isso equivale a

$$
\text { PIB do agregado II }=\left(V A_{1}-T_{1}\right)-\left[\left(V A_{1}-T_{1}\right)\left(\frac{x_{i 1}}{X_{i}}\right)\right] \text {, }
$$

em que $V A_{1}$ é o valor adicionado a preço de mercado, gerado pelo setor agropecuário; $T_{1}$, valor dos impostos líquidos (exclui subsídios) sobre a produção do setor agropecuário; e $\left[\left(V A_{1}-T_{1}\right)\left(\frac{x_{i 1}}{X_{i}}\right)\right]$, proporção do valor adicionado $(V A)$ a custo de fatores do setor da agropecuária, gerada sobre os insumos do próprio setor.

Parré (2000) diferenciou-se de Montoya e Finamore (2001), visto que não extraiu o valor adicionado a custo de fatores, gerado sobre os insumos originados do setor da agropecuária no cálculo da renda da produção rural, o que pode incorrer em superestimativa do PIB do agregado II. Mais especificamente, no método de Parré (2000) não consta o segundo termo da equação 10, isto é, segue-se a seguinte equação:

$$
\text { PIB do agregado II }=\left(V A_{1}-T_{1}\right) .
$$




\subsection{Dimensionamento do Agregado III}

Na definição do agregado III ou produção agroindustrial (PAI), Montoya e Finamore (2001) utilizaram a Classificação Internacional Uniforme das atividades econômicas. Há algumas diferenças nos métodos de dimensionamento propostos por Montoya e Guilhoto (2000) e por Parré (2000). No entanto, ambos consideraram a questão acerca do fato de que há setores em que a atividade é totalmente associada ao agronegócio e setores em que a atividade pode englobar produtos que não pertençam ao agronegócio.

No cálculo do valor da produção agroindustrial considera-se o valor adicionado gerado pelas indústrias de base agrícola que compõem o setor agroindustrial. No entanto, na delimitação do setor agroindustrial, há controvérsias a respeito do método correto. Geralmente, o objetivo do estudo é o que define a metodologia. Na definição dos setores que compõem a agroindústria, há estudos que consideram a participação percentual do produto rural no valor total dos insumos usados na transformação; há os que dão maior relevância à natureza do processamento; e há, ainda, os que tomam como base o nível tecnológico ou a concentração de mercados, entre outros fatores. Nesse contexto, Moretto et al. (2002) sugeriram a adoção de critérios da Classificação Industrial Uniforme (CIIU - versão 2) de todas as atividades econômicas. De acordo com essa classificação, o setor agroindustrial, conforme a agregação aqui usada, é formado pelas seguintes atividades: Madeira e mobiliário; Indústria têxtil; Artigos de vestuário; Produtos de couro e calçado; Produtos do café; Beneficiamento de produtos vegetais; Abate de animais; Indústria de laticínios; Fabricação de açúcar; Fabricação de óleos vegetais, tortas e farelos; e Fabricação de produtos alimentares e bebidas

Feito isso, nesta pesquisa, segue-se Montoya e Finamore (2001) e estima-se o valor da produção agroindustrial ou agregado III, da seguinte forma:

$$
\text { PIB do agregado III }=P A I=\left(V A_{A I}-T_{A I}\right)-\left(V A_{A I}-T_{A I}\right) \frac{x_{A I A}}{X_{A I}},
$$

em que $V A_{A I}$ é o valor adicionado a preço de mercado gerado pelo setor da agroindústria; e $T_{A I}$ o valor dos outros impostos líquidos sobre a produção, pago pela agroindústria.

O segundo termo da equação 12 é a proporção do valor adicionado a custo de fatores da agroindústria sobre o insumo agroindustrial utilizado no setor agropecuário. Esse montante é extraído novamente, já que está incluso na mensuração do PIB do agregado I; portanto, a sua exclusão diminui problemas de superestimativas. Entretanto, Parré (2000) não fez essa exclusão e estimou o PIB da agroindústria de acordo com a seguinte equação:

$$
\text { PIB do agregado III }=P A I=\left(V A_{A I}-T_{A I}\right) \text {. }
$$




\subsection{Dimensionamento do Agregado IV}

Montoya e Finamore (2001) e Parré (2000), no cálculo da distribuição final (DIF) ou do agregado IV, tomaram como base o valor agregado dos setores de transporte e comércio e do setor de serviços. Considerando que todos os setores da economia estão presentes nesses setores, é coerente o uso de uma ponderação (ou rateio), com vistas em direcionar ao agronegócio apenas a parcela referente aos produtos agropecuários e produtos da agroindústria na demanda final do estado de Minas Gerais. A base de cálculos nesta etapa é a produção interna (PI). Parte-se do conceito de produção nacional ou demanda final global de produtos nacionais e importados (DFGP). A DFGP inclui os impostos líquidos consumidos pelos investimentos, pelas exportações para o exterior e para o resto do Brasil, pela variação de estoque, pelo governo e pelas famílias. Desse montante, excluem-se as importações do exterior e do resto do país (IER) e os impostos indiretos líquidos ligados à demanda final (IIL). Matematicamente, a produção interna $(P I)$ é:

$$
P I=D F G P-I I L-I E R \text {. }
$$

Para estimar a parcela do valor adicionado associada ao comércio e transporte de produtos agropecuários e agroindustriais, os valores da margem de comercialização $(M C)$, respectivos a esses setores, são considerados como parcela do valor da produção do setor de transporte e comércio e do setor de serviços que devem ser associados ao agronegócio. A fórmula de cálculo da margem de comercialização $(M C)$ é:

$$
M C=V A_{t}-T_{t}-\left[\left(V A_{t}-T_{t}\right)\left(\frac{x_{t 1}}{X_{t}}\right)\right]+V A_{s}-T_{s}-\left[\left(V A_{s}-T_{s}\right)\left(\frac{x_{s 1}}{X_{s}}\right)\right]
$$

em que

- $V A_{t}$ e $V A_{s}$ são o montante de $V A$ a preço de mercado, gerado pelos setores transporte e comércio, e serviços, respectivamente;

- $T_{t}$ e $T_{s}$, outros impostos líquidos sobre a produção desses setores;

- $\left[\left(V A_{t}-T_{t}\right)\left(\frac{x_{t 18}}{X_{t}}\right)\right]$, proporção do valor adicionado a custo de fatores do setor transporte e comércio obtida sobre os insumos transporte e comércio utilizados no setor agropecuária; e

- $\left[\left(V A_{s}-T_{s}\right)\left(\frac{x_{s 15}}{X_{s}}\right)\right]$, proporção do valor adicionado a custo de fatores do setor serviços, gerada sobre o insumo serviço utilizado no setor da agropecuária. 
Mais uma vez, Parré (2000) distinguiu-se de Montoya e Finamore (2001), pois incluiu o valor adicionado a custo de fatores do setor de transporte e comércio e também do setor de serviços gerada sobre o insumo serviço utilizado no setor da agropecuária, que faz parte do PIB do agregado I. No entanto, fica claro que essa inclusão no PIB do agregado IV constitui-se um problema de dupla contagem.

No cálculo do agregado IV, ou de distribuição final (DIF), ambos os trabalhos seguem a equação apresentada a seguir:

$$
\text { PIB do agregado IV }=D I F=\left(\frac{\sum_{k} Y_{i k}+\sum_{k} Y_{8 k}}{P I}\right) M C .
$$

Na equação 16, $Y_{1 k}$ é o somatório da demanda final de produtos da agropecuária e $Y_{8 k}$, o somatório da demanda final de produtos do setor da agroindústria. As expressões $P I$ e $M C$ correspondem à produção interna e à margem de comercialização, respectivamente. Matematicamente, a estimação da renda do agronegócio de Minas Gerais, sob a ótica da produção, segue os somatórios dos resultados obtidos das equações definidas no Quadro 1, o que corresponde a dizer que o PIB do agronegócio representa a soma do PIB dos agregados I, II, III e IV.

Quadro 1. Método de dimensionamento da renda do agronegócio usado no estudo

\begin{tabular}{|c|c|}
\hline Agregados do agronegócio & Fórmulas \\
\hline $\begin{array}{c}\text { Agregado I - Fornecimento de } \\
\text { insumos à agropecuária }\end{array}$ & $\sum_{i=1}^{n}\left[\left(\frac{x_{i 1}}{X_{i}}\right) X_{i}-\left(\frac{x_{i 1}}{X_{i}}\right) C_{i}\right]+m_{1}^{R}+m_{1}^{P}$ \\
\hline Agregado II - Produção agropecuária & $\left(V A_{1}-T_{1}\right)-\left[\left(V A_{1}-T_{1}\right)\left(\frac{x_{i 1}}{X_{i}}\right)\right]$ \\
\hline Agregado III - Produção agroindustrial & $\left(V A_{A I}-T_{A I}\right)-\left(V A_{A I}-T_{A I}\right) \frac{x_{A I A}}{X_{A I}}$ \\
\hline Agregado IV - Distribuição Final & $\left(\frac{\sum_{k} Y_{i k}+\sum_{k} Y_{8 k}}{P I}\right) M C$ \\
\hline
\end{tabular}

Nota: Versão adaptada do método proposto em Montoya e Finamore (2001).

\subsection{Fonte e tratamento dos dados}

Neste trabalho, foram utilizadas as informações provenientes da matriz de insumo-produto Minas Gerais-Resto do Brasil, de 1999, sendo estas as últimas informações disponíveis sobre a estrutura intersetorial da economia mineira. A 
elaboração desta matriz foi feita ${ }^{5}$ a partir de dados preliminares das Contas Nacionais e Regionais de 1999, fornecidas pelo IBGE, usando o modelo desenvolvido por Guilhoto et al. (2002a). O nível de agregação setorial compreende 33 atividades, estando a demanda intermediária agregada em 18 setores, o que permite destacar a agroindústria. Na definição dos setores que compõem cada agregado do agronegócio, seguiram-se as agregações apresentadas no Quadro 2, anexo.

\section{Resultados e discussão}

No dimensionamento do PIB do agronegócio de Minas Gerais utilizou-se a metodologia proposta por Montoya e Finamore (2001), que supera, principalmente, o problema de estudos anteriores relativo à estimativa da renda do agregado I. Ademais, na presente pesquisa, optou-se por incluir as importações interestaduais e internacionais de insumos na renda dos setores fornecedores de insumos e implementos agrícolas para a agropecuária (agregado I), tal como feito em Parré (2000). Na Tabela 1 pode-se visualizar a diferença no dimensionamento da contribuição do agronegócio para a economia mineira quando usada a metodologia $\mathrm{A}$, que considera as compras interestaduais e internacionais de insumos e quando escolhida a metodologia B, na qual tal procedimento não é feito.

Tabela 1. Produto Interno Bruto, a custo de fatores ${ }^{6}$, do agronegócio de Minas Gerais em 1999 (em mil reais)

\begin{tabular}{lcccc}
\hline \multirow{2}{*}{ Agregados } & \multicolumn{2}{c}{ Metodologia A } & \multicolumn{2}{c}{ Metodologia B } \\
& PIB $_{\mathbf{c f}}$ & $\boldsymbol{\%}$ & PIB $_{\mathrm{cf}}$ & $\%$ \\
\hline Agregado I - setor a montante & 5.397 .199 & 20,73 & 1.916 .075 & 8,49 \\
Agregado II - produção agropecuária & 7.168 .052 & 27,53 & 7.168 .052 & 31,78 \\
Agregado III - produção agroindustrial & 3.731 .550 & 14,33 & 3.731 .550 & 16,54 \\
Agregado IV - distribuição final & 9.739 .870 & 37,41 & 9.739 .870 & 43,18 \\
Setor a jusante - agregado III + agregado IV & 13.471 .420 & 51,74 & 13.471 .420 & 59,73 \\
\hline PIB do agronegócio de Minas Gerais & 26.036 .671 & 100,00 & 22.555 .547 & 100,00 \\
\hline
\end{tabular}

Fonte: Resultados da pesquisa.

Notas: Metodologia A: inclui transações interestaduais e importações do exterior na quantificação do agregado I. Metodologia B: não inclui transações interestaduais e importações do exterior no agregado I.

\footnotetext{
${ }^{5}$ Matriz estimada e gentilmente disponibilizada pelo Professor Doutor Joaquim José Martins Guilhoto, do Departamento de Economia da Faculdade de Economia, Administração e Contabilidade da Universidade São Paulo.

${ }^{6}$ PIB a preços de mercado excluído o valor referente aos impostos indiretos líquidos que incorrem sobre a produção de cada setor.
} 
Ao analisar a estrutura do agronegócio, conforme a metodologia A, por meio da composição do valor adicionado, observa-se que, da renda total deste setor, $20,73 \%$ referem-se ao agregado I ou ao setor a montante. São atividades que suprem a produção rural com insumos e implementos agrícolas em Minas Gerais. Nota-se que a produção agropecuária mineira (agregado II) detém parcela de $27,53 \%$ do PIB do agronegócio. O agregado III, que é composto pelos setores de produção agroindustrial (processamento e armazenagem), possui parcela de 14,33\% do PIB do agronegócio de Minas Gerais, enquanto as atividades ligadas à distribuição final dos bens agrícolas (agregado IV) têm a maior parcela $(51,74 \%)$ da renda do agronegócio mineiro. Conclui-se que o agregado IV é o setor de maior representatividade no agronegócio estadual.

A maior representatividade dos setores de distribuição final dos produtos de origem agrícola está ligada, sobretudo, à grande contribuição do setor de serviços para a economia mineira. As atividades de serviços contribuem com $46 \%$ da renda total de Minas Gerais, e o do comércio, principalmente varejista, contribui fortemente para a maior participação do setor de serviços no PIB do estado. Lado a lado com a alta contribuição do setor de comércio varejista está o setor de transportes de Minas Gerais, com percentuais muito baixos no total da renda do estado.

Segundo dados do Informativo Indicadores Rurais (CNA, 2006), em 2005, a agroindústria nacional (agregado III) contribuiu com 30\% para o PIB do agronegócio do País, cenário distinto da economia de Minas Gerais, considerando-se a baixa representatividade da agroindústria mineira (14,33\%) no PIB do agronegócio estadual. Percebe-se, pois, que a identificação de gargalos para o desenvolvimento da agroindústria mineira é importante. Segundo Lemos (2001), uma das razões ligadas aos problemas para tornar a agroindústria atividade promotora de desenvolvimento tem origem no processo de industrialização induzido do estado. Acreditava-se que a ampliação e a diversificação do complexo metal-mecânico mineiro induziriam, automaticamente, ao desenvolvimento agroindustrial, juntamente ao crescimento da base produtiva agropecuária. No entanto, somente a região do Triângulo Mineiro experimentou, efetivamente, o dinamismo da agroindústria, sem que seus avanços se reproduzissem para outras regiões do estado. A região norte de Minas é um exemplo, marcada pela ausência de atividades de processamento que impedia, portanto, a expressividade da base agroindustrial.

Nesse contexto, pode-se afirmar que a idéia de "crescimento natural" da agroindústria de Minas Gerais culminou no fortalecimento do setor agropecuário orientado para o mercado. A estrutura agroindustrial mineira é ineficaz para absorver e desfrutar do desenvolvimento da agropecuária, já que é marcada, sobretudo, por poucas unidades de processamento e por pouca diversificação. Ademais, conforme dito, a base empresarial agroindustrial mineira é pouco dinâmica. De acordo com dados da $\mathrm{FGV}^{7}$, apenas 7 das 44

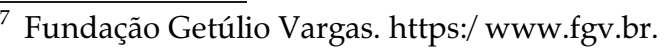


maiores empresas agroindustriais do Brasil estão sediadas em Minas Gerais. O resultado é a presença de um setor agroindustrial muito aquém de sua base agropecuária. As importâncias relativas dos agregados II e III na produção do agronegócio mineiro respaldam tal avaliação.

Prosseguindo a análise dos resultados, identifica-se que a renda do agronegócio de Minas Gerais foi, em 1999, de R \$26.036.671 mil, que é, cerca de 3,6 vezes superior à da agropecuária, mais precisamente, $\mathrm{R} \$ 7.168 .052$ mil (Tabela 1). No mesmo ano, o valor do PIB mineiro foi de $\mathrm{R} \$ 87.490 .933$ mil, segundo dados do IBGE, o que indica que o agronegócio contribui com $29,76 \%$ deste total. Paralelamente, a participação de Minas Gerais no agronegócio do Brasil, em 1999, foi de 9,66\%, considerando o valor do PIB do agronegócio brasileiro de R\$ 269.467.700 ${ }^{8}$ mil. Esta é uma contribuição relativamente alta, visto que se iguala à representatividade da economia mineira no valor total do PIB do País, no mesmo período. Segundo Guilhoto et al. (2000), a participação do agronegócio no PIB brasileiro foi, em 1999, em torno de $28,81 \%$. Comparada com a participação do PIB do agronegócio mineiro na renda estadual $(29,76 \%)$, constata-se que a estrutura produtiva, identificada para o agronegócio mineiro em 1999, indica maior aproximação do perfil do agronegócio do estado às tendências da economia nacional, no que se refere à importância desse setor para a economia.

Os resultados obtidos quando aplicada a metodologia B, que desconsidera as transações relativas às importações nacionais e internacionais de Minas Gerais no agregado I, indicam que o valor do PIB do setor a montante, obviamente, sofreu redução. O setor a montante apresentou, nessa situação, renda equivalente a R $\$$ 1.916 .075 mil, o que implica redução de $20,73 \%$ na participação do agregado I no agronegócio mineiro, na metodologia A, para 8,49\%, na metodologia B (Tabela 12). Esse resultado é importante, pois aponta forte relação de dependência da produção rural de Minas Gerais com relação aos demais estados do Brasil e do mercado internacional, no que se refere à demanda de insumos e implementos agrícolas.

A modificação na metodologia da mensuração do agregado I implica, certamente, em diminuição no valor da renda do agronegócio mineiro. As importações interestaduais e do exterior, originárias da agropecuária, totalizaram $\mathrm{R}$ \$ 3.481.123 mil. A exclusão desse volume fez a renda do agronegócio mineiro reduzir de $\mathrm{R} \$ 26.036 .671$ mil para $\mathrm{R} \$ 22.555 .548$ mil. Desse modo, a importância do agronegócio na renda da economia de Minas Gerais, embora ainda consideravelmente substancial, passou, em 1999, a representar 25,78\% da renda estadual, em comparação aos $29,76 \%$, caso tais transações fossem computadas.

De acordo com Guilhoto et al. (2000), a estimativa da participação do agronegócio no PIB do País foi, em 1999, em torno de 28,81\%. Ao comparar essa informação com a participação do PIB do agronegócio mineiro na renda estadual,

${ }^{8}$ Este valor está contabilizado conforme a ótica do PIB a preço de mercado. 
constata-se que a estrutura produtiva do agronegócio mineiro, em 1999, revela perfil próximo das tendências da economia nacional, no que se refere à importância do agronegócio para a economia.

De acordo com Malassis (1969), a estrutura do agronegócio pode refletir o grau de desenvolvimento de uma região. Segundo os parâmetros do autor, a economia mineira apresentou, em 1999, o nível de economia alimentar industrializada, dada a participação inferior a um terço do valor total do agronegócio da agropecuária, junto à maior representatividade do segmento a jusante. Um estudo feito para o estado do Paraná, por Moretto et al. (2002), aponta o mesmo nível de desenvolvimento para a economia paranaense, embora nesse estado, assim como em Minas Gerais, a agropecuária desempenhe papel de grande importância na economia.

Um estudo realizado para a Bahia, por Guilhoto e Ichihara (2006), indica que, em 1999, a economia baiana se enquadrava no perfil de economia pré-industrial, dada a participação de $42 \%$ da produção rural no PIB do agribusiness baiano. O resultado repetiu na análise da estrutura do agronegócio de Pernambuco, feita por Neto e Costa (2005). Em Pernambuco, as atividades de "dentro da porteira" contribuíram, em 1999, com 40,9\% da renda total do agronegócio, o que remete à economia pernambucana como em vias de industrialização, ou pré-industrialização.

Em síntese, verificou-se que os setores ligados a processamento, armazenamento e distribuição de produtos agrícolas (setor a jusante) ofereceram maior contribuição relativa $(51,74 \%)$ na formação da renda do agronegócio de Minas Gerais. A agropecuária (agregado II), embora com peso relativo menor, também representou parcela importante $(27,5 \%)$ na renda do agronegócio estadual. É relevante também citar que a metodologia usada nesta pesquisa apresentou contribuições, visto que mostrou avanços em relação aos métodos anteriores, contornando alguns problemas de estimativa e dupla contagem, bem como a dificuldade de estimativa da renda dos setores fornecedores de insumos à agropecuária (agregado I), cuja contribuição para a renda do agribusiness mineiro esteve próxima a $21 \%$.

\section{Conclusões}

A pesquisa utilizou a matriz de insumo-produto de Minas Gerais de 1999 para aplicação de uma versão modificada do método de dimensionamento do agronegócio proposta por Finamore e Montoya (2001), os quais apresentaram avanços em relação a estudos anteriores, tal como a dificuldade de estimativa da renda do agregado I. A partir de informações sobre a participação do agronegócio de Minas Gerais na economia do estado e da composição do agronegócio, obtiveram-se importantes conclusões. 
Primeiramente, observou-se que o agronegócio mineiro desempenhou papel fundamental na economia estadual, considerando a geração de renda equivalente a 29,76\% da renda total de Minas Gerais, em 1999, e a contribuição de 9,66\% para a renda do agronegócio do País. No que refere a sua capacidade de geração de renda, o montante foi da ordem de $\mathrm{R} \$ 26.036 .670$ mil, que é equivalente a 3,6 vezes a renda do setor agropecuário - R \$ 7.168.052 mil - em 1999. Na análise das contribuições individuais de cada agregado componente do agribusiness mineiro, identificou-se a contribuição da ordem de $20,73 \%$ na formação do PIB do agronegócio de Minas Gerais por parte dos setores a montante (agregado I). Além disso, as importações de insumos representam parcela importante na produção dos setores fornecedores de insumos para a agropecuária, o que revela grande dependência dessas atividades para com a provisão de matérias-primas originárias de outros estados do Brasil e do mercado externo.

Quando analisada a contribuição da atividade agropecuária para a formação do PIB do agronegócio mineiro, o montante corresponde a $27,53 \%$ da renda do agribusiness estadual. No entanto, na avaliação da produção agroindustrial mineira observou-se parcela relativamente baixa, o que definiu este agregado como o de menor peso relativo $(14,33 \%)$ na produção do agronegócio estadual e evidencia a necessidade de um processo de dinamização, visando a sua estruturação, para que haja condições de absorver o desenvolvimento de sua base agrícola. As atividades de distribuição final (agregado IV) contribuíram com $37,41 \%$ do PIB do agronegócio mineiro, mostrando, portanto, que os setores a jusante tiveram maior representatividade no agronegócio de Minas Gerais e que o estado seguiu a tendência de descentralização da estrutura produtiva do agronegócio no País. A maior representatividade do setor de distribuição se deveu ao setor de serviços, que domina a estrutura setorial do estado de Minas Gerais.

$\mathrm{Na}$ caracterização do grau de desenvolvimento ligado à estrutura do agronegócio, a economia mineira apresentou, em 1999, características de economia alimentar industrializada, considerando a participação da produção agropecuária próxima de um terço do valor total do agronegócio. Em suma, os resultados da pesquisa explicitam que as atividades do agronegócio em Minas Gerais detêm participação importante na renda do PIB estadual e do agribusiness nacional. Tais resultados são significativos porque evidenciam a magnitude do setor e, portanto, o grau de importância para a dinâmica da economia mineira.

Faz-se importante destacar os problemas relativos à indisponibilidade de matrizes de insumo-produto oficiais atualizadas, os quais constituem obstáculos à realização de maiores estudos relacionados com investigação de relações e contribuições das atividades econômicas para a economia como um todo. Por fim, em que pese as questões aqui levantadas, buscou-se, principalmente, oferecer contribuições para aprofundar o conhecimento das características estruturais do agronegócio mineiro, que devem ser complementadas por outras investigações, dentre as quais, possíveis avanços ligados à etapa metodológica de 
quantificação da renda do agregado IV, em especial. O intuito seria aperfeiçoar a ponderação usada para direcionamento à renda do agronegócio apenas a parcela dos produtos agropecuários e agroindustriais que integram o PIB dos setores de transporte, comércio e serviços. Outra linha de estudo contundente é a avaliação dos obstáculos inerentes ao maior desenvolvimento da agroindústria mineira, passando pela identificação dos problemas ligados a esta atividade, o que poderia auxiliar na formulação de políticas públicas que visem ao desenvolvimento e crescimento desse setor econômico e, conseqüentemente, ao dinamismo de todos os setores ligados ao agronegócio de Minas Gerais.

\section{Referências Bibliográficas}

ARAUJO, N.B; WEDEKIN, I; PINAZZA, L. Complexo agroindustrial: o “agribusiness" brasileiro. São Paulo: Agroceres, 1990. 238 p.

CONFEDERAÇÃO NACIONAL DE AGRICULTURA. Indicadores rurais. Informativo Indicadores Rurais, Brasília, Distrito Federal, n. 66, janeiro/fevereiro, 2006.

DAVIS, J.H.; GOLDERG, R.A. A concept of agribusiness. Boston: Harvard Graduate Scholl of Business Administration, 1957. 152 p.

DIAWARA, M. Dimensionamento do Agronegócio no estado de Minas Gerais. Viçosa: UFV, 2002, 82 p. Tese (Mestrado Em Economia Aplicada) - Universidade Federal de Viçosa, 2002.

FERNANDES, C. L. L., A inserção de Minas Gerais na economia nacional: uma análise insumo-produto inter-regional. Nova Economia, Belo Horizonte, número especial, p. 85-178, 1997

FIGUEIREDO, M.G., BARROS, A. L. M., GUILHOTO, J. J. M. Relação econômica dos setores agrícolas do Estado do Mato Grosso com os demais setores pertencentes tanto ao Estado quanto ao restante do Brasil. Revista de Economia e Sociologia Rural. Vol. 43, nํ3, Brasília. Jul./Set. 2005.

FURTUOSO, M.C.O. O Produto Interno Bruto do Complexo Agroindustrial Brasileiro. Tese de doutorado. Piracicaba, 1998. 278 p. - Universidade de São Paulo/ESALQ/USP.

GUILHOTO, J. J. M., ICHIHARA, S. M. PIB do agronegócio baiano, 2004. Bahia Agrícola, v.7, nํ. 2, abril, 2006.

GUILHOTO, J. J. M., FURTUOSO, M. C. O, BARROS, G.S. C., O agronegócio na economia brasileira, 1994 a 1999. Relatório Metodológico. Confederação 
Nacional da Agricultura e Pecuária. CEPEA - Edição especial, 50 anos. Setembro, 2000.

GUILHOTO, J.J.M.; SESSO FILHO, U.A.; LOPES, R.L.; HILGEMBERG, C.M.A.T.; HILGEMBERG, E.M. Nota metodológica: construção da matriz insumo-produto utilizando dados preliminares das contas nacionais (compact disc). In: Encontro Brasileiro de Estudos Regionais e Urbanos, 2., São Paulo, 2002. Anais. Belo Horizonte: Associação Brasileira de Estudos Regionais, 2002.a.

LEONTIEF, W. A economia de insumo-produto. São Paulo: Fundo de Cultura, 1983. 227 p.

LEMOS, M. B. Estrutura e Dinâmica. In: MINAS GERAIS DO SÉCULO XXI. Banco de Desenvolvimento de Minas Gerais (BDMG). Belo Horizonte: Rona Editora, volume VI, Integrando a indústria para o futuro, p. 9 a 110, 2002.

MALASSIS, L. La structure et l'evolution du complexe agri-industruel d'aprés la compatibilté nationale française. Economies et Societés. Paris, v.2, n.9, p.1667-1687, set. 1969.

MILLER, R.E. Regional and interregional input-output analysis. In: ISARD, W. et al.

MONTOYA, M.A., GUILHOTO, J.J. M. O agronegócio brasileiro entre 1959 a 1995: dimensão econômica, mudança estrutural e tendências. In: MONTOYA, M.A. PARRÉ, J.L. O agronegócio brasileiro no final do século XX. Passo Fundo: UPF, 2000.

MONTOYA, M.A.; FINAMORE, E. B. Evolução do PIB do agronegócio brasileiro de 1959 a 1995: uma estimativa na ótica do valor adicionado. Revista Teoria e Evidência Econômica. FEA-UPF, Passo Fundo, RS. V.9, N.16, P. 09-24, Maio de 2001.

MORETTO, A.C., RODRIGUES, R.L.; PARRÉ, J.L. Tendências do Agronegócio no Paraná: 1980 a 1995. In: CUNHA, M.S. da; SHIKIDA, P.F.A.; ROCHA JÚNIOR, W.F. Agronegócio Paranaense: potencialidades e desafios. Cascavel: Edunioeste, p.33-55, 2002.

NETO, D.L.A., COSTA, E.F. Dimensionamento do PIB do agronegócio em Pernambuco. Revista de Economia e Sociologia Rural.Vol. 43, no04, Brasília. Out./Dez. 2005.

NUNES, E. P.; CONTINI, E. Complexo Agroindustrial Brasileiro: Caracterização de Dimensionamento. Brasília: Associação Brasileira de Agribusiness, 109 p., 2001. 
PARRÉ, J.L. O agronegócio nas macrorregiões brasileiras: 1985 a 1995. Piracicaba, 2000.191p. Tese (Doutorado) - Escola Superior de Agricultura “Luiz de Queiroz", Universidade de São Paulo.

PARRÉ, J.L., GUILHOTO, J. J. M. A importância econômica do agronegócio para a região sul do Brasil. Análise Econômica, Porto Alegre, v. 19, n. 35, p. 37-54, 2001.

PORSSE, A. A. Notas metodológicas sobre o Dimensionamento do PIB do Agronegócio do Rio Grande do Sul. Documentos FEE. Porto Alegre: FEE, nº . 55, 62 p., 2003.

ROSSETI, J. P. Contabilidade Nacional: uma abordagem introdutória. $2^{\text {a }}$ edição. São Paulo. Atlas, 1980.

SANTANA, A. C. de. A dinâmica do complexo agroindustrial e o crescimento econômico no Brasil. Viçosa, 1994. 302 p. Tese (Doutorado) - Universidade Federal de Viçosa. 


\section{Apêndice}

Quadro 1. Classificação setorial do agronegócio mineiro

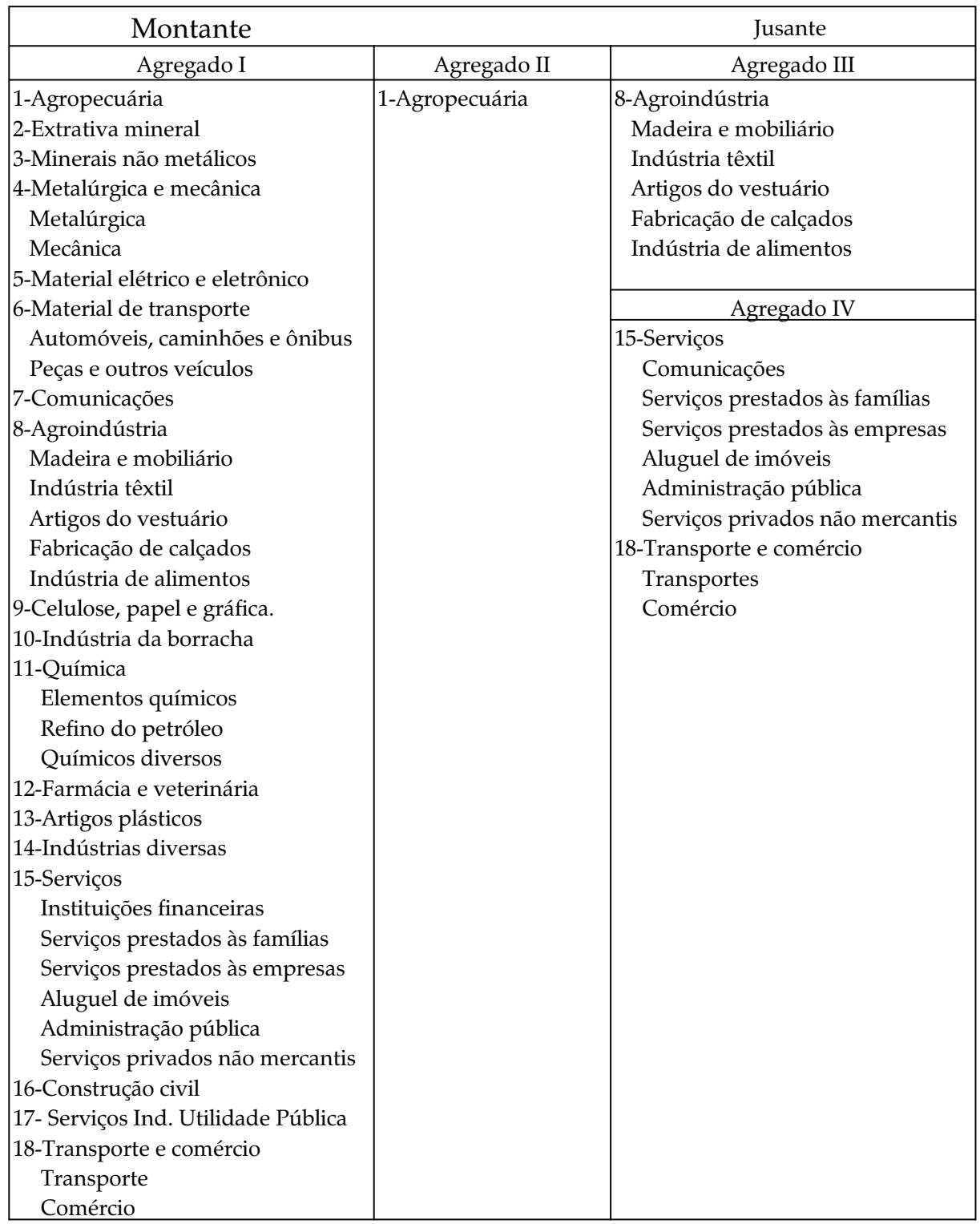

Fonte: Matriz insumo-produto de Minas Gerais - Resto do Brasil de 1999. 